\title{
Surgical Management of Pulmonary Hydatid Cyst
}

\author{
Dr. Ashok Surybhanji Gajbhiye, Dr. Mangala M.Sonak, Dr. Malikchand M. \\ Meshram, Dr. Amrish P. Kathod, Rekha S. Gajaralwar.
}

\begin{abstract}
Aim of conservative surgical technique to achieve complete removal of cyst and early mobilization in the management of pulmonary hydatid cyst. Material and method:-The prospective study was conducted at Indira Gandhi Government medical college, Nagpur. During the study period seventy two patients operated upon for hydatid disease were evaluated pre and postoperatively. Results: - 47 male and 25 female patients were treated with enucleation 33(45.83 \%), cystostomy 26 (36.11\%), segmentectomy 05(6.94 \%), pericystectomy $04(5.56 \%)$ and lobectomy in 04(5.56\%) patients. In 51(70.83\%) patients capitonnage was performed. Mortality in one patient (1.39\%) with $11.11 \%$ morbidity was observed in the present study. Conclusion: - From the present study we conclude that conservative surgical procedure achieved complete removal of cyst and early mobilization in the management of pulmonary hydatid cyst. Bronchial communication should be closed by purse string sutures. These simple procedures are safe, reliable and successful. However radical procedures should only be carried out in selected patients with specific indications.
\end{abstract}

\section{Introduction:}

Hydatidosis is an endemic zoonosis in Middle Eastern countries, the Mediterranean coast and South Africa. Hydatid disease is known to occur in many parts of world, but is rare in India because man, dog, sheep/cattle trio is uncommon in this subcontinent. Liver remains the commonest site and lung involvement ranges from $5 \%$ to $44 \%[1,2,3,4]$. Not enough is known of the epidemiology and epizootiology of hydatidosis in India .Preventive measures include observance of strict hygienic standards, exercising of utmost caution in feeding dogs with meat and systemic medication of dogs with arecoline hydrobromide, the antihelmintic of choice. Lung hydatid disease is an endemic problem in Mediterranean countries, and the ideal surgical management for it is still debated $[5,6,7,8]$.

Simple thoracic hydatid cysts may remain asymptomatic for a long time. As they enlarge, some may show symptoms such as slight chest pain, nonproductive cough and dyspnoea resulting from compression of adjacent organs. Rupture of the hydatid cyst into an adjacent bronchus may occur because of vigorous coughing and expectoration of a large amount of salty sputum consisting of mucus, hydatid fluid and occasionally fragments of the cystic membrane. The scolices can be found by microscopy in the sputum. When rupture of the hydatid cyst occurs into the pleural space, hydro-pneumothorax develops, followed by empyema.

The diagnosis of simple thoracic hydatid cyst is not difficult. Since no effective treatment is available, once the diagnosis of hydatid cyst is made or even suspected, operation becomes mandatory in order to avoid the complications such as anaphylaxis, infection of cyst, pressure symptoms and dissemination due to leak or rupture. A gradual reduction in the antibody reaction after 1-4 years of surgery indicates a complete cure. The definitive cure for pulmonary hydatidosis is still surgical $[9,10,11]$. Several surgical procedures were described for the treatment of pulmonary hydatid cysts using Barrett technique in 1952 (intact endocystectomy without preliminary aspiration), pericystectomy (i.e Perez-Fontana operation) and lobectomy as described by different authors $[12,13,14,15]$.

In adult, some authors have reported the successful use of thoracoscopic procedures for the treatment of pulmonary hydatid disease. In pediatrics, only two similar reports were found: one in the French literature and the other in the English literature. Both have confirmed the feasibility of the thoracoscopic approach in children with pulmonary hydatid cysts. It follows the same principles of the open technique, which include sterilization of the cyst with scolicidal agents (e.g., hypertonic saline, savlon) and complete excision of cyst. They did not close the fistula because the patient showed a transient degree of increased airway pressure and desaturation, which was found to be owing to increased secretion in the right side of endotracheal tube .The rapid development of laparoscopic techniques, has encouraged surgeons to replicate principles of conventional hydatid surgery using a minimally invasive approach. Several reports have confirmed the feasibility of laparoscopic hepatic and lung hydatid surgery in uncomplicated hydatid cyst as reported by various author $[8$, $13,16,17,18]$.

The management of the cystic cavity in complicated or intact cysts, Delbet first described the method called capitonnage, which is the folding of the pericystic zone by sutures. Crausaz reported that purse string sutures from the base of the pericystic cavity upward could be used to obliterate the cavity. It is generally agreed, 
that the most important point in the management of the residual pericystic cavity is closure of patent bronchial openings [19,20] and Conservative management of a ruptured pulmonary hydatid cyst by [29].

Thus, the purpose of prospective study is to look at the features at clinical presentation, management of pulmonary hydatid cyst and postoperative complications.

\section{Patients and methods:}

The prospective study was conducted at Indhira Gandhi Government Medical College, Nagpur over a period of ten years from May 2002 to April 2012. During the study period we studied seventy two cases. All the cases were investigated fully in terms of blood investigation, chest radiography and Computed Tomography of thorax (Fig-1). Patient's undergone conservative surgery in the form of enucleation of cyst or cystotomy and removal after aspiration of the cyst were with radical procedure like pericystectomy, lobectomy and pneumonectomy. Patients having both lung and liver hydatid cyst or unfit due to anesthesia were excluded from the study.

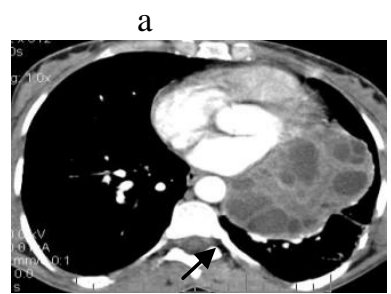

CT scan showing a)multiple daughter cyst

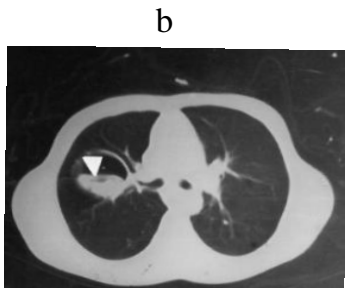

b) Water lily sign .

FIG- 1] PULMONARY HYDATID CYST [a-c] .

The principles of surgical intervention were evacuation of the cyst with removal of the endocyst (Fig-2), avoidance of contamination and management of the residual cavity. Normal lung tissue was preserved as much as possible in the operation. Lateral or Anterolateral thoracotomy was performed in all the patients. Cavity managed either by drainage or capitonnage. Postoperative Albendazole $800 \mathrm{mg}$ for three months was given in those patients in whom the cyst got ruptured while they were being enucleated at operation or it was ruptured preoperatively. Bronchial communication was seen in all the cases and major leaks sutured with purse string suture. Minor leaks left unsutured. Problems during surgery includes 1] Infection - either due to adhesion or Hemorrhage or friable lung tissue - cutting through of sutures.2] Sometimes difficulty occur during identification of cyst. 3] Rupture due to dissemination or aspiration pneumonitis. To solve these problems we have given preoperative antibiotic, Albendazole and double lumen endotracheal tube intubation to decreased risk of aspiration pneumonitis. After 24 hours post operative chest radiography was done in all the patients.
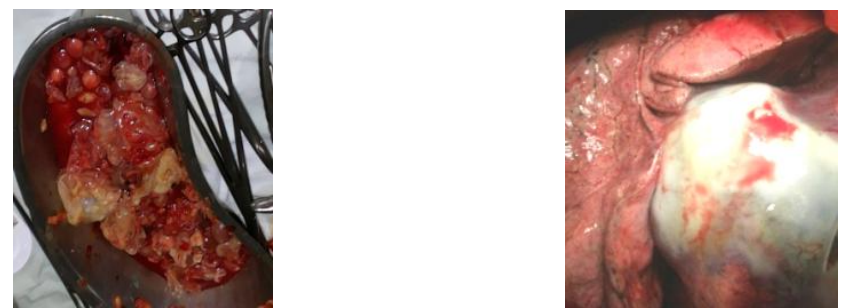

FIG-2] LAMINATED MEMBRANE (Intraoperative and Postoperative)

\section{Results:-}

The present study was a hospital based prospective study of pulmonary hydatidosis. Seventy two patients of pulmonary hydatid cyst were treated surgically, majority belonged to the age group 13 to 58 years and male to female ratio was 1.88:1 (Table-1).The youngest patient was 1 year old male who had ruptured hydatid cyst and presented with tension pnueumothorax. The oldest patient was 58 year male.

Table-1] Age and sex wise distribution of cases ( $n=72)$.

\begin{tabular}{|l|l|l|}
\hline \multirow{2}{*}{ Age group (years) } & Sex & \\
\cline { 2 - 3 } & Male & Female \\
\hline $11-20(\mathrm{n}=08)$ & 05 & 03 \\
\hline $21-30(\mathrm{n}=24)$ & 18 & 06 \\
\hline $31-40(\mathrm{n}=20)$ & 14 & 06 \\
\hline $41-50(\mathrm{n}=16)$ & 09 & 07 \\
\hline $51-60(\mathrm{n}=04)$ & 01 & 03 \\
\hline Total & $47(65.28)$ & $25(34.72)$ \\
\hline
\end{tabular}


Pain in the chest was the commonest presenting symptom in $45(64.50 \%$ ) cases, Haemoptysis in $5(6.94 \%)$ cases. Hyperpyrexia, Pneumothorax and respiratory distress were observed in one case each. $19(26.39 \%)$ patients were asymptomatic. History of having pet animals like dog and or sheep was available only in $8(11.11 \%)$ patients. Right lung was involved in 49 cases $(68.05 \%)$ and the left lung in $19(26.39 \%)$ cases. $3(4.17 \%)$ patients had bilateral disease. Uncomplicated cysts were found in 62 patients $(86.11 \%)$ of which single cyst was found in 57(91.494\%) cases and multiple cysts in the rest of 5(8.06\%) cases.

\section{Fig.3] Doughnut showing various surgical procedures.}

\section{No. of patients}

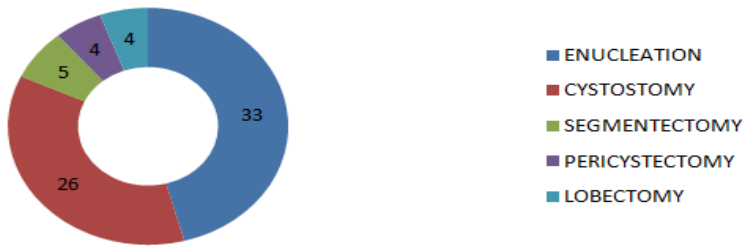

All patients were undergone surgical techniques like enucleation was done in33 (45.83\%) cases. Cystotomy and removal after aspiration was carried out in $26(36.11 \%)$, segmentectomy in $05(6.94 \%)$, pericystectomy in $04(5.56 \%)$ and lobectomy was performed in 04(5.56\%) patient (Fig-2). Residual cavity was managed by capitonnage in $51(70.83 \%$ ) cases. Complete removal of cyst was achieved in all the cases.

The location of cysts in all patients was as intrapulmonary in 64(91.42\%) cases, extrapulmonary in $2(2.85 \%)$ cases. Bilateral cyst in $4(5.71 \%)$ cases was observed in the present study. Staged thoracotomy was done in patients with bilateral disease that is three month after first thoracotomy.

In the follow up during the study period, all the patients were doing well. Albendazole $800 \mathrm{mg}$ once a day for three months was given in those who had rupture of cyst either preoperatively or at the time of enucleation. Two of our patients developed recurrence of cyst with mortality in one patient. Morbidity was observed in 8 patients $(11.11 \%)$ only. Complications were 1] Empyema in 2(2.85\%) patients, Bronchopleural fistula in $1(1.4 \%)$ and wound infection in $5(7.14 \%)$ patients which was managed conservatively .....

\section{Discussion:-}

Pulmonary hydatidosis in man is frequently encountered in sheep and cattle raising regions of the world. The numerous reports and surveys available from India reveal its occurrence in most of the states of which Andhra Pradesh and Tamil Nadu predominate. Reports of pulmonary hydatidosis from Andhra Pradesh, Gujarat, Himachal Pradesh, Maharashtra, Rajasthan, Tamil Nadu and Utter Pradesh are reviewed. Surgery is undoubtedly the sure method of cure for this parasitic disease and antihelmintics are of little value [1]. The incidence of hydatid disease in a particular place is dependent upon the incidence in the intermediate host like sheep, pig and cattle in that area Stock FE (1970). The mass miniature radiographic study was conducted by Purriel (1973) revealed that the lung hydatid cyst has a high incidence between 5 and 9 years of age and a second high incidence after the age of 50 years.

Normal method of transmission (Fig-4) is by ingestion of eggs, cyst can also develop in the lung if eggs are inhaled. Within 8 hours of swallowed eggs, the oncosphere can be found in the portal venous system and within 21 days, the larval form becomes vesicular and visible to the naked eyes. The brood capsule then detaches by mechanical interference to form daughter cysts which are free from "hydatid sand" in the cyst cavity. The lung hydatid cyst develops extremely slowly and it was observed that the pulmonary hydatid cyst starts developing in childhood and grows for 5 to 20 years before being diagnosed. The laminated membrane in lung hydatid cyst is very thin, so it usually ruptures before it reaches an enormous size.

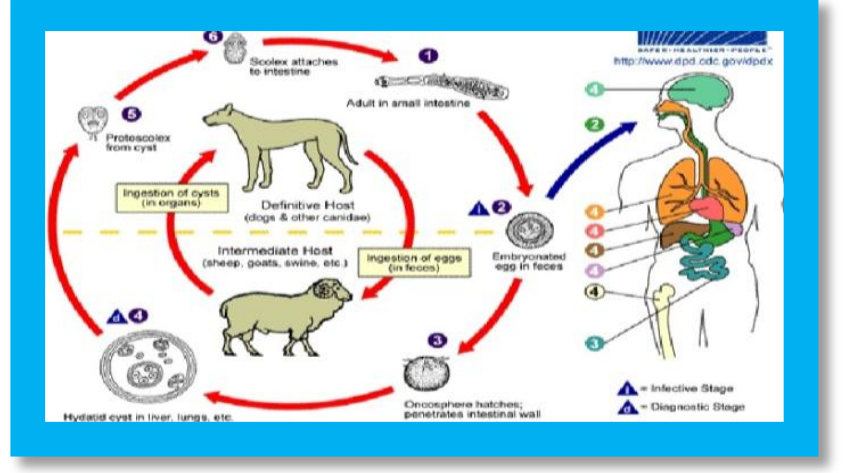

FIG- 4] LIFE CYCLE $\quad-\quad$ HYDATID CYST. 
In the present study there were 47 males, 25 females and age range was 13 to 58 years. Male to female ratio was 1.88:1. The male predominance was also observed by other authors $[2,3,5,7,14,21,22]$. The high incidence in male is probably because males are more exposed to animal contact, environmental and dietary changes than females. In the present series right lung was involved in 49 cases $(68.06 \%)$ and the left lung in $19(26.39 \%$ ) cases. The percentages of the cyst locations were $68.06 \%$ in the right lung, $26.39 \%$ in the left, $50.0 \%$ in the lower lobe, and $30.56 \%$ in the upper, which in probably related to the difference of blood flow between bilateral lungs and the anatomical feature of the lower lobe. Because of the elasticity and compliance of the lung parenchyma, hydatid cysts typically grow faster in the lung than in other organs. Therefore larger cysts are more common in the lung, where they can grow from a few millimeters to 5 centimeters in 1 year. The prevalence of hydatid cysts was greater in the right lung and in the lower lobes of both lungs was also observed by other authors $[3,5,23]$.

Pain in the chest was the commonest presenting symptom in $45(62.50 \%)$ cases, Haemoptysis in $5(6.95 \%)$ cases. Hyperpyrexia, Pneumothorax and respiratory distress were observed in one case each. $17(23.61 \%)$ patients were asymptomatic in the present series. Out of 57 patients, most common presenting symptoms were cough in 41 patients and 12 patients were asymptomatic. Chest X-ray showed a rounded shadow in 42 patients, 19 cases were of vigorous size $>10 \mathrm{~cm}$ or more as observed by the author [2]. Cough and chest pain were the prominent symptoms in the majority of cases [22]. Out of 1230 patients, the symptoms were cough in $678(55.1 \%)$ cases, haemoptysis in $353(28.7 \%)$, chest pain in 567 (46.1\%), sputum in $380(30.9 \%)$, and asymptomatic in $142(11.5 \%)$. The number of cases showing no sign in physical examination was 455 $(37 \%)$, however $418(33.9 \%)$ cases had dullness on percussion of the chest, $372(30.2 \%)$ cases had weak breath sounds on auscultation of the chest and $364(29.8 \%)$ had enlargement of the liver as observed by [14]. Giant pulmonary hydatid cyst and complicated hydatid cyst are usually symptomatic. Common presenting symptoms of giant pulmonary hydatid cyst are compression symptoms such as dry cough, while ruptured cyst can cause productive cough, chest pain, dyspnoea and very rarely anaphylactic shock. Giant pulmonary hydatid cyst is a rare clinical entity and is defined as more than $10 \mathrm{~cm}$ in size $[15,24]$.

Preoperative diagnosis was based primarily on chest roentgenograms and leads to correct diagnosis in 59 cases $(81.94 \%)$. Similar findings were also observed by the author [3]. Chest radiography gave a correct diagnosis in $96.4 \%$ of the patients as observed by the author [12]. An additional CT scan was required in 12 cases. The diagnosis was established intraoperatively in one case. Ultrasonography was performed on 1103 cases and the diagnostic rate was $89.1 \%$. Casoni's test was performed on 1021 cases and the positive rate was 87.9\% (897); 911 cases had indirect Coomb's test and the positive rate was 86.6\% (798) and 692 cases had positive result for the immune-electrophoresis test $(75.9 \%)$ as reported by the author [14]. Contrast enhanced computed tomography of thorax revealed a large rounded, well circumscribed loculated cyst with little remaining lung tissue on right side. IgG Elisa for ecchinococcous granulosus was positive. Patient was diagnosed as a case of giant pulmonary hydatid cyst and treated by surgical resection of cyst [15].

Table-2] Review of pulmonary hydatid surgery.

\begin{tabular}{|l|l|l|l|l|l|l|}
\hline Series & $\begin{array}{l}\text { No. } \\
\text { patient }\end{array}$ & $\begin{array}{l}\text { Enucleati } \\
\text { on }\end{array}$ & $\begin{array}{l}\text { Cystostom } \\
\mathbf{y}\end{array}$ & $\begin{array}{l}\text { Segmentecto } \\
\text { my }\end{array}$ & $\begin{array}{l}\text { Pericystecto } \\
\text { my }\end{array}$ & $\begin{array}{l}\text { Lobectom } \\
\text { y }\end{array}$ \\
\hline Dakak et al 3 & $\mathbf{4 2 2}$ & $\mathbf{2 0 2}$ & $\mathbf{1 7 1}$ & $\mathbf{4 0}$ & - & $\mathbf{9}$ \\
\hline $\begin{array}{l}\text { Yalcinkaya et al } \\
22\end{array}$ & $\mathbf{3 0}$ & $\mathbf{2 8}$ & $\mathbf{2}$ & - & - & - \\
\hline Yena et al 25 & $\mathbf{1 1}$ & - & - & - & $\mathbf{6}$ & $\mathbf{5}$ \\
\hline Burhan et al 12 & $\mathbf{3 5}$ & $\mathbf{2 4}$ & $\mathbf{0 9}$ & - & - & $\mathbf{2}$ \\
\hline Biswas et al 26 & $\mathbf{4 2}$ & $\mathbf{2 6}$ & $\mathbf{1 0}$ & $\mathbf{4}$ & - & $\mathbf{2}$ \\
\hline Present series & $\mathbf{7 2}$ & $\mathbf{3 3}$ & $\mathbf{2 6}$ & $\mathbf{0 5}$ & $\mathbf{0 4}$ & $\mathbf{0 4}$ \\
\hline
\end{tabular}

Lobectomy was performed intraoperatively in $4(5.56 \%)$ patients in cysts that cause parenchymal damage by involving more than $50 \%$ of a lobe or that are associated with such sequelae as chronic abscess, bronchiectasis or severe hemorrhage in the present series. Similar finding were also observed by the different author $[3,11,12,16,25,26]$. Most of the patients were treated with enucleation 33(45.83\%) for peripheral cysts larger than $3 \mathrm{~cm}$ in diameter and cystostomy $26(36.11 \%)$ with removal of content after aspiration and in $51(70.83 \%)$ patients capitonnage was performed for residual cavity in the present series. When the exocyst is opened bronchial openings are closed first and then the cavity is obliterated by means of purse string sutures along the bronchus. When the cystic cavity opens downward, the residual cavity need not be obliterated if bronchial openings are closed and pericystic lung tissues have good expansion and no air leak. It should be noted that distorted ligation of bronchus, incomplete haemostasis and closure of residual cavity are risk factors for infection and abscess formation. Segmentectomy was performed in 05(6.94\%) for those peripheral cysts less than $2.5 \mathrm{~cm}$ in diameter having risk of rupture after enucleation. Pericystectomy was performed in $04(5.56 \%)$ 
patients having dense adhesions or destruction of pulmonary parenchyma. If hydatid cyst is concomitant with empyema, pleural drainage must be performed in the stage. If the lung cannot expand, decortications or thoracoplasty is required. Pulmonary resection must be avoided as much as possible. However segmental resection, wedge resection and lobectomy will be justified when the size and the number of cysts and the degree of infection exclude lesser procedures.

Out of 422 cases, enucleation and capitonnage was performed in 202 cases, wedge resection in 40, cystotomy and capitonnage in 171 and lobectomy in 9 patients. The high risk patients were treated with Albendazole ( $10 \mathrm{mg} / \mathrm{kg} / \mathrm{day})$ for a period of 3 months postoperatively. Mean follow up period was 2 to 19 years and detected recurrence in 3(0.71\%). Most 296 patients presented with a solitary lung cyst. The rest were found to have multiple cysts in one or more lobes. 87 of 422 also had cysts in the liver, 19 in the spleen and 1 in the pancreas as observed by the author [3].

Out of 32 patients, 18 were treated with thoracotomy and 14 with thoracoscopy by the author [13]. The mean operative duration in the thoracoscopy group was $95.21 \mathrm{~min}$ compared to $137.77 \mathrm{~min}$ in thoracotomy group $(\mathrm{P}<0.0001)$. Postoperative analgesia requirement was less in the thoracoscopic group (mean 4.92 days) compared to that in the thoracotomy group (mean 13.94 days; $\mathrm{P}<0.0001$ ). The intercostal drain was removed earlier in the thoracoscopic group (mean 5 days) than in the thoracotomy group (mean 8.83 days; $\mathrm{P}<0.0001$ ). The postoperative hospital stay was 8.35 days (mean) in thoracoscopic group and 18.77 days in the thoracotomy group $(\mathrm{P}<0.0001)$. The most serious morbidity was wound infection, with three cases $(16.66 \%)$ in the thoracotomy group and one $(7.11 \%)$ in the thoracoscopy group. There was no operative mortality and no recurrence during the follow up period.

In a ten year old boy with pulmonary hydatid cysts treated with Video assisted thoracoscopic surgery assisted minithoracotomy with hydatid cyst enucleation and capitonnage. The patient developed a lung abscess postoperatively and had to undergo lobectomy in their study reported by the author [16].

71 patients with pulmonary hydatid cysts were treated surgically by the author [21] and cystotomy and closure of bronchial openings were performed in all patients. Obliteration of the residual cavity by imbricating sutures from within (capitonnage) was achieved in 39 patients (group 1). There were 34 patients with intact cysts and 37 patients with at least one complicated cyst. The average diameter of the cysts was 6.4 $\mathrm{cm}$, and the mean number of cysts per patient was 1.4. The surgical outcome was assessed in group 1 patients and in patients who had undergone closure of bronchial openings without capitonnage (group 2; $\mathrm{n}=32$ ). The total hospitalization time was $5.0 \pm 5.0$ days for group 1 and $5.9 \pm 6.9$ days for group $2(p=0.91)$. Stay in the intensive care unit was $1.64 \pm 1.22$ days in group 1 and $1.60 \pm 1.52$ days in group $2(\mathrm{p}=0.90)$. The duration of air leak was $2.56 \pm 4.73$ days in group 1 and $2.38 \pm 4.74$ days in group $2(p=0.87)$. There was no significant difference between groups in the development of empyema (1 patient in group 2 only) and prolonged air leak (5 patients in group 1 and 4 in group 2). No significant difference was reported in the rate of recurrence in their series. Similar findins were observed by the author [20].

A retrospective review was conducted on 30 patients with pulmonary hydatid cysts during the last 3 years by the author [22], Cystotomy and capitonnage were performed in 28 of the 30 cases $(93.4 \%)$. The transdiaphragmatic route or simultaneous laparotomy was preferred when the liver was involved by [28]. Albendazole was used in four patients with multiple hydatid cysts due to probable recurrence in the postoperative period. A single lobe was affected in 22 patients. Unilateral multiple foci were present in four patients and bilateral multiple foci in four. Six patients had concomitant liver cysts. No recurrences were seen on control chest radiographs during the last 2 years follow up.

Surgical treatment for hydatid cysts in 364 patients were underwent by the author [4] and all of whom had multiple localizations. To avoid two or three staged operations for the treatment of 460 hydatid cyst localizations in 364 patients, a collective 381 operations were performed. They performed median sternotomy simultaneous bilateral thoracotomy and unilateral thoracotomy with a transdiaphragmatic approach. The number of operations and periods of hospitalization were reduced.

Eleven cases of the pulmonary hydatid disease were operated in Mali by the author [25] retrospective from 1960 to 2000. Patients were aged between 4 and 42 years. The male to female was 1.75:1. Seven patients had at least a sign of complicated cyst. Out of a total of 12 cysts, 9 were located to the right lung. The treatment of the cyst consisted in a cystectomy accompanied by an atypical resection of the parenchyma on 6 patients and a typical resection of the attacked lobe on 5 others. The operating effects were complicated in 5 cases.

Retrospectively analyzed 35 children ranging in age from 3 to 13 years treated for pulmonary hydatidosis during four year period by the author [12] and 35 patients had a collective total of 48 cysts. Twenty seven patients had a single cyst, 7 had unilateral multiple cysts and one patient had bilateral multiple cysts. Six patients had multiple coexisting liver cysts. The 33 pulmonary cysts were intact and uncomplicated. Of the total 48 cysts, 34 were larger than $5 \mathrm{~cm}$ in diameter. Fever, cough, and dyspnea were the most common symptoms and Conservative surgical treatment was carried out in 33 of the 35 children (94\%). There were few postoperative complications and no mortality or recurrence in their series. Combined medical treatment can be 
given but not as an alternative to surgery. Simultaneous surgical procedures for coexisting liver cysts may be preferred because of the lower morbidity rates and hospitalization.

Out of 42 patients, cysts were removed in 36 patients, bronchial leaks were sutured and residual cavities were obliterated by the author [26]. Out of rest 6 patients, having dense adhesions or destruction of pulmonary parenchyma, 4 had segmentectomy and 2 had lobectomy.

In the present series mortality was seen in one patient (1.39\%). A 65 years old patient died on the $6^{\text {th }}$ post operative day from pulmonary embolism. Morbidity was observed in 8 patients $(11.11 \%)$. In the medical literature, morbidity rates for all hydatid cysts surgery ranges from $3.5 \%$ to $27 \%$, whereas mortality rates range from zero to $2 \%[5,9,10,20,21,23,25,26,27]$. Postoperative complications occurred in 8 patients, prolonged air leak in 4 patients, pleural effusion in 2patient. Pneumothorax and wound infection was reported in one case each. The mean hospital stay was 9 days and during follow up period 2 recurrences were reported in the present study. In a follow up period of 2 to11 years, 4 recurrences were reported by the author [2].

\section{Conclusion: -}

From the present study we conclude that conservative surgical procedure is the treatment of choice in management of uncomplicated pulmonary hydatidosis. Bronchial communication should be closed by purse string sutures. These simple procedures are safe, reliable and successful. However radical procedures should only be carried out in selected patients with specific indications.

\section{References:-}

[1]. Anantaraman M (1983) pulmonary hydatidosis in India: An overview. Lung India 1(4):123-7.

[2]. Shalabi RI, Ayed AK, Amin A (2002) 15 years in surgical management of pulmonary hydatidosis. Annals of thoracic and cardiovascular surgery. 8(3):131-134.

[3]. Dakak M, Yucel O, Kavaldi K (2009) Intrathoracic extrapulmonary hydatid cyst: Review of 33 cases. Trakya Univ Tip Fak Derg.26 (2):125-129.

[4]. Ceran S, Sunam GS, Gormus N (2002) Cost effective and Time saving Surgical Treatment of Pulmonary Hydatid Cysts with Multiple Localization. Surg Today.32 (7); 573-576(2002)

[5]. Beg MH, Mansoor T (2002) pulmonary hydatidosis- a surgical experience.JIMA; 100(1); 1-3.

[6]. Bharti S, Bharti B (2002) Hydatid disease of lungs-unusual cause of haemoptysis. Indian Pediatrics 39; 1062-1063.

[7]. Recep T, Sema O,Nuri S(2000) Pulmonary hydatid cysts in children .Ann med sci;9;59-62.

[8]. Mehta KD, Gundappa R, Contractor R et al(2010) Comparative Evaluation of Thoracoscopy Versus Thoracotomy in the Management of ung Hydatid Disease. World Journal of Surgery. 34(8): 1828-1831

[9]. Erdogan A, Avten A, Kabukch H (2005) One - stage transthoracic operation for the treatment of right lung and liver hydatid cysts. World J Surg.29 (12):1680-6.

[10]. Aletras H, Symbas PN (2002) Hydatid disease of the lung. General thoracic surgery, $5^{\text {th }}$ ed.Philadelphia: Lippincott Williams and Wilkins.1113-22.

[11]. Kanat F, Turk E, Aribas OK(2004) Comparision of pulmonary hydatid cysts in children and adults.ANZ J Surg.74(10):885-9.

[12]. Burhan K,Vedat B,Onder $\mathrm{O}$ et al (2002) Conservative surgical treatment of pulmonary hydatid disease in children: An analysis of 35 cases. 32(9): 779-783.

[13]. Chowbey PK, Shah S, Khullar R et al (2004) Minimal Access Surgery for Hydatid Cyst Disease: Laparoscopic, Thoracoscopic, and Retroperitoneoscopic Approach . Journal of Laparoendoscopic and advanced Surgical Techiniqes.13 (3):159-165.

[14]. Mingbai WU, Liwei Z, Zhongxi Q (2005) Surgical treatment for thoracic hydatidosis: review of 1230 cases.118 (19):1665-1667.

[15]. JAkhtar J,Khan NA,Baneen U et al(2012) Giant pulmonary hydatid cyst mimicking elevated diaphragm: A diagnostic dilemma.11(2):122-123.

[16]. Parelkar SV, Gupta RK, Shah H et al (2009) Experience with video-assisted thoracoscopic removal of pulmonary hydatid cysts in children. Journal of Pediatric Surgery. 44(4): 836-841

[17]. Tullu MS, Lahiri KR, Kumar S et al (2005) Minimal access therapy in pediatric pulmonary hydatid cysts. Pediatric Pulmonology. 40(1): 92-95

[18]. Mallick MS Al-Qahtani A, Al-Saadi MM et al (2006) Thoracoscopic treatment of pulmonary hydatid cyst in a child. Benha M.J.23 (3):407-409.

[19]. Sonmez K, Turkeyilmaz K, and Demirogullari B, et al (2001) Hydatid cysts of the lung in childhood: is capitonnage advantageou s? Ann Thorac Cardiovasc Surg .7:11-13.

[20]. Sokouti M, Golzari S, Aghdam B (2011) Surgery of uncomplicated pulmonary hydatid cysts: Capitonnage or uncapitonnage? International Journal of surgery.9 (3):221-224.

[21]. Çelik M, Senol C, Keles M, et al (2000) surgical treatment of pulmonary hydatid disease in children: report of 122 cases. J Pediatr Surg. 35:1710-1713.

[22]. Yalcinkaya I, Er M, Ozbay B (1999) surgical treatment of hydatid cyst of the lung: review of 30 cases. European Respiratory Jour.13 (2):441-444.

[23]. Usluer O, Ceylan KC, Kaya S (2010) surgical management of pulmonary hydatid cysts.Tex Heart Inst J.37 (4):429-434

[24]. Karaoglanoglu N, Kurkcuoglu IC, Gorguner M(2001) Giant hydatid lung cysts.Eur J Cardiothorac Surg.19(6):914-7.

[25]. Yena S, Sanogo Z, Keita et al (2002) Surgery for pulmonary hydatid cyst in Mali. Ann Chir. 127(5):350-5.

[26]. Biswas B,Ghosh D,Bhattacharjee R et al (2004) One stage surgical management of hydatid cyst of lung \& liver by right thoracotomy \& phrenotomy. Indian Journal of Thoracic and Cardiovascular surgery. 20(2):88-90.

[27]. Aribas OK, Kanat F, and Turk E (2002) Comparision between pulmonary and hepatopulmonary hydatidosis.Eur J Cardiothorac Surg. 21 (3):489-96.

[28]. KaramustafaogluYA, Reyhan G, Kuzucuoglu M (2011) One stage surgical management for lung and liver hydatid diseases: Management of liver and lung cysts. European Surgery. 43(4): 233-235.

[29]. ZampoliM, Zar H (2007) Conservative management of a ruptured pulmonary hydatid cyst. Pediatric Pulmonology. 42(12):1229-32. 